\title{
Moral distress among nurses working in Covid-19 wards: a cross-sectional study in 2021
}

\section{Mina Pooresmaeil}

Ardabil University of Medical Sciences

Masoumeh Aghamohammadi ( $\nabla$ agamohammadim@gmail.com )

Ardabil University of Medical Sciences

\section{Research Article}

Keywords: Moral Distress, Corona virus, Covid-19, Nurse, Ardabil

Posted Date: October 6th, 2021

DOI: https://doi.org/10.21203/rs.3.rs-934292/v1

License: (c) (i) This work is licensed under a Creative Commons Attribution 4.0 International License. Read Full License 


\section{Abstract \\ Background}

Covid-19 is an emerging disease, which has confronted nurses with new moral distress. This study aims to determine the moral distress and its related factors among nurses working in the covid- 19 wards of Ardabil city in Iran.

\section{Methods}

This cross-sectional descriptive study evaluated 159 nurses working in the covid-19 wards of Imam Khomeini hospital -as the only hospitalization center for the patients with covid-19 in Ardabil, 2021. The instruments used included a personal-occupational information form and Corley's moral distress scale. Data analysis was performed using descriptive and inferential statistics (Pearson correlation coefficient, independent t-test and one-way analysis of variance) in SPSS v22.

\section{Results}

The mean and standard deviation of the frequency and intensity of the nurses' moral distress were estimated $52.28 \pm 5.24$ and $51.54 \pm 5.86$, respectively, which indicated the moderate level of moral distress in the both dimensions. The item "I hesitate to tell the patient or the patient's family about his condition and treatment" $(4.74 \pm 0.75)$ showed the most moral distress based on the intensity and the phrase "too much work reduces the quality of my work" $(4.81 \pm 0.55)$ caused the most moral distress in the frequency dimension. The results indicated a significant relationship between the intensity and frequency of moral distress with the type of nurses' employment $(P<0.05)$. Moreover, a significant relationship was observed between the nurses' position and the frequency $(P=0.04)$, and the nurses' work experience and the intensity of moral distress $(P=0.02)$.

\section{Conclusions}

It seems that providing the necessary training for how to deal with the moral distress in new waves of the disease and using the experiences of the experienced nurses in this field are essential due to observing the moderate level of moral distress among nurses working in covid-19 wards.

\section{Background}

Morality is an inseparable part of human life, which explains the right from the wrong or the good from some bad behaviors (1). Ethics is necessary in occupations in addition to the personal life, which is even more necessary in the nursing profession due to the spiritual behaviors associated with nurses' responsibility in saving patients' lives (2). The importance of doing moral work becomes even more since 
nurses work in a system, which is constantly changing and evolving. Further, the society demands the high quality services of nurses based on the existing conditions (3).

Moral behavior is an important feature of nurses, which has a significant effect on the treatment process (4). Caring the patients in various physical, mental, psychological, and spiritual aspects is always associated with the moral considerations. Nursing is inherently considered as the moral profession since it emphasizes the care of others (5). Nowadays, paying attention to legal and ethical issues in nursing is more important due to the advancement of technology, medical and pharmaceutical equipment (6). Nurses are forced to face different aspects of ethics since they usually present at the patients' beds and communicate closely with them causing the moral decisions and comments (7). Therefore, they face an unpleasant experience called moral distress (MD) (8).

Initially described by Andrew Jameton in 1984, MD is defined as knowing what to do in an ethical situation, but not being allowed to do it. He reported that the moral distress causes the anger, frustration, anxiety, headache, sadness, grief, depression, as well as conflict between doing the right thing and organizational rules (9). Corley considered the moral distress as a major problem in nursing (10). Moral distress is an emotional and mental disorder in which a person commits a mistake while being aware of the right decision and having the necessary ability to judge and make decisions due to real and organizational moral limitations $(11,12)$. Nurses are exposed to moral distress due to the factors such as shortage of time and lack of specific organizational rules, which disrupts their decision-making process and psychological balance (13). Various studies referred to the level of moral distress in nurses. Abbaszadeh et al. indicated the moderate moral distress of the nurses in different wards (14). However, Altaker et al. demonstrated that the high levels of the moral distress were observed among the nurses working in the intensive care units (15). Moreover, Jalali et al. reported the high moral distress of the nurses in emergency department (16).

Based on the studies, the type of the environment of the work is effective in the occurrence of nurses' moral distress (17). The emergency department due to the direct contact with the patients and staff, high workload, and lack of the necessary facilities $(18,13)$, and the intensive care unit for high exposure of the nurses to the patient mortality are considered as the stressful situations (19). During Coronavirus Disease (COVID-19) Pandemic, problems such as the increased stress, faster care, use of personal protective equipment, not allowing patients' families to visit due to their risk of infection, and many other factors make the situation more critical in addition to previous stressors (20). Moreover, working in unfamiliar environments, participating in unknown processes, workforce shortages, existing more the patients in need of the urgent care at the same time, fear of infection, new waves of the disease, deadly nature, and disease disability are challenged the nurses' decision-making between doing what is morally right and doing what is cost-effective $(20,21)$.

The occurrence of moral distress is predictable in nurses following the spread of the disease, which causes the placement of nurses at the forefront of the struggle and endangering their lives $(22,23)$. The serious moral and emotional stress is caused due to the unprecedented experience of covid-19 disease, 
which is a new global pandemic (24), as well as the ongoing and difficult work of nurses during epidemics (25) and the respect for the patient's rights referring to the effort to balance all conditions (26). Moreover, nurses caring for the patients with covid-19 disease faced the problems such as unknown work environment, exposure to the disease, lack of experience in seeking new diseases, as well as more public and media attention, which could expose the nurses to the moral challenges (27), affect adversely the quality of care, and interfere with the patient treatment. Therefore, it seems necessary to be aware of the level of moral distress in nurses in these wards. In this regard, this study aims to determine the level of moral distress and its related factors in the nurses working in covid-19 wards of Ardabil city.

\section{Methods}

\section{Study design and participants}

In this cross-sectional descriptive study, all the nurses working in the covid-19 wards of Imam Khomeini Hospital in Ardabil including emergency, inpatient, dialysis, intensive care units, and nursing office in 2021 who met the inclusion criteria were included in the study based on the census method $(n=159)$. Inclusion criteria included having at least a bachelor's degree in nursing, having worked in the covid-19 wards for at least one month, and the absence of life crises such as divorce, death of loved ones, etc. during the past six months.

\section{Measurements}

Data collection tools included a form of the personal-occupational characteristics including age, gender, marital status, level of education, duration of nursing work, workplace ward, job position, shift work, and type of employment and the Corley's Moral Distress Scale (MDS). This questionnaire has 21 items, which measures the frequency and intensity of the moral distress with five-point Likert and the options are scored 0-5 in each section. The scores are considered from 0 (not at all) to 5 (very high) in the intensity section, and from 0 (never) to 5 (frequent) in the frequency section. Scores 0-70, 70-140, and 140-210 indicate the mild, moderate and sever moral distress, respectively. Numerous studies used this questionnaire. Roshanzadeh et al. calculated the validity and reliability of this tool in Iran.

Ten experienced people in the field of ethics examined its validity and its content validity index was determined $88 \%$. Moreover, its reliability was calculated $93 \%$ by using Cronbach's alpha coefficient (28), which indicated its appropriate reliability.

\section{Data collection and ethical considerations}

The study was approved by the ethics code from the Ethics Committee in Biomedical Research at Ardabil University of Medical Sciences (ARUMS) (ethic code IR.ARUMS.REC.1399.462). The researchers obtained written informed consent from each participant as one of the criteria for them to join the study. The consent form outlined that participation is voluntary, participant anonymity will be protected, participants may withdraw their participation whenever they desire with no repercussions. All methods were carried out in accordance with relevant guidelines and regulations. After then, the participants were provided with 
the questionnaires after explaining the objectives of the study to them. Data collection was considered as the self-reported. In this study, the questionnaires were distributed among the nurses working in covid-19 wards (223 people), $71.3 \%$ (159 people) of which were completely filled.

\section{Data analysis}

The collected data were analyzed by using descriptive (frequency, mean, and standard deviation) and inferential statistics (Pearson correlation coefficient, independent t-test, and one-way analysis of variance) in SPSS version 22. A two-sided p-value of less than 0.05 was considered statistically significant.

\section{Results}

\section{General characteristics of the participants}

The mean age of the respondents was $31 \pm 5.7$ years; $83.6 \%$ were women and more than half $(56 \%)$ were married and had a mean work experience of $8.35 \pm 5.6$ years (Table 1 ).

Table 1: Frequency distribution of demographic characteristics of participants 


\begin{tabular}{llcc}
\hline Variables & Categories & Number & Percentage \\
\hline Gender & Male & 26 & 16.4 \\
\multirow{2}{*}{ Marital status } & Female & 133 & 83.6 \\
& Single & 70 & 44 \\
position & Married & 89 & 56 \\
& Nurse & 144 & 90.5 \\
& Head nurse & 6 & 3.8 \\
Work shift & Supervisor & 9 & 5.7 \\
& Fixed morning & 17 & 10.7 \\
& Fixed evening & 2 & 1.2 \\
& Fixed night & 0 & 0 \\
& Shifts in circulation & 140 & 88.1 \\
& Permanent & 77 & 48.42 \\
& Under-a-contract / Contractual & 42 & 26.41 \\
& Conscription law's conscripts & 16 & 10.07 \\
& Temporary-to Permanent & 24 & 15.1 \\
\hline
\end{tabular}

\section{Level of moral distress}

Based on the results, 157 of 159 nurses had moderate moral distress in frequency and all the nurses reported the moderate levels of moral distress in intensity. Mean and standard deviation of frequency and intensity scores of moral distress in the studied nurses were $52.28 \pm 5.24$ and $51.54 \pm 4.86$, respectively, which indicated the moderate level in both dimensions of moral distress (Table 2).

Table 2: Frequency and intensity of moral distress in participants

\begin{tabular}{lcccc}
\hline Moral distress & Low & Moderate & High & Mean \pm SD \\
\cline { 2 - 4 } & $\mathbf{N}(\%)$ & $\mathbf{N}(\%)$ & $\mathbf{N}(\%)$ & \\
Frequency & $1(0.62)$ & $157(98.74)$ & $1(0.62)$ & $52.28 \pm 5.24$ \\
Intensity & 0 & $159(100)$ & 0 & $51.54 \pm 4.86$ \\
\hline
\end{tabular}


As shown in Table 3, among 21 items related to the moral distress questionnaire of nurses working in covid-19 wards, the items "I hesitate to tell the patient or the patient's family about his condition and treatment" with the highest mean and standard deviation (4.74 \pm 0.75$)$ and "I care about patients' feelings and emotions" with the lowest mean and standard deviation $(1.32 \pm 1.11)$ caused the severe moral distress in the nurses. Moreover, the items "too much work reduces the quality of my work" and "I have experienced conflict with my colleagues" with a mean and standard deviation of $4.81 \pm 0.55$ and $1.35 \pm 1.06$, respectively, showed the highest and lowest frequency among the items of moral distress.

Table 3: Mean and standard deviation of moral distress items in participants 
The pressure of reducing organizational costs forces me to provide low quality care.

Too much work reduces the quality of my work.

$4 / 53 \pm 0 / 87 \quad 4 / 81 \pm 0 / 55$

When the patient's death was certain, I applied for an organ

$1 / 52 \pm 1 / 10$

$1 / 39 \pm 1 / 18$ donation with the patient's family.

I have struggled with superiors and / or managers at work.

$1 / 09 \pm 1 / 07 \quad 0 / 90 \pm 0 / 82$

I accept the patient's family request to continue caring for the

$2 / 76 \pm 1 / 22$

$2 / 73 \pm 1 / 26$

patient, although I feel it is of little benefit to the patient.

In most cases, I consider myself ultimately responsible for the

$3 / 28 \pm 1 / 22$

$3 / 25 \pm 1 / 23$ patient's health status.

When I perform resuscitation, I know that it delays my death.

$2 / 22 \pm 1 / 62 \quad 2 / 36 \pm 1 / 68$ Most people do not approve of me as a nurse deserves and do not

$1 / 53 \pm 1 / 24$ $1 / 52 \pm 1 / 25$ respect me.

I do not talk about death with a dying patient, even if her family

$2 / 19 \pm 1 / 46$

$2 / 14 \pm 1 / 49$ asks me to.

I hesitate to tell the patient or the patient's family about her

$4 / 74 \pm 0 / 75$

$4 / 69 \pm 0 / 78$ condition and treatment.

I follow the doctor's instructions regarding incurable patients, even

$2 / 92 \pm 1 / 56$

$1 / 50 \pm 1 / 10$ if I think it is unnecessary.

I care about the feelings and emotions of my patients.

$1 / 32 \pm 1 / 11 \quad 4 / 56 \pm 0 / 83$

I may disagree with other members of the treatment team about

$1 / 71 \pm 1 / 02$

$1 / 75 \pm 1 / 08$ treating the patient.

I have continued to care for a sick patient who is not in a promising

$4 / 63 \pm 0 / 82$

$3 / 11 \pm 1 / 63$ condition while no one has decided to end the patient's life.

Sometimes I do not have the opportunity to share my feelings and $1 / 34 \pm 1 / 06$ $1 / 40 \pm 1 / 15$ experiences with my colleagues.

I have experienced conflict with my colleagues.

$1 / 36 \pm 1 / 05 \quad 1 / 35 \pm 1 / 06$

Sometimes, despite the patient's request to hear the truth, I do not

$2 / 28 \pm 1 / 32$ $2 / 36 \pm 1 / 40$ tell her the truth for the sake of expediency. 
responsibilities.

I have involved my feelings and emotions in caring for the patient. $\quad 1 / 06 \pm 1 / 08 \quad 1 \pm 0 / 93$

I helped a doctor who I thought was doing the wrong thing.

$3 / 76 \pm 1 / 37 \quad 4 / 08 \pm 1 / 25$

In order to maintain my professional competence, I keep up with

$4 / 24 \pm 0 / 93 \quad 4 / 26 \pm 0 / 89$ new developments.

\section{Factors associated with moral distress}

One-way analysis of variance and independent t-test were used for determining the relationship between the demographic characteristics of the participants and their moral distress. Based on the results, a significant relationship was observed between the type of employment and the intensity and frequency of the moral distress $(p<0.05)$. Further, there was a significant relationship between the job position and the frequency of moral distress $(P=0.04)$. Nurses who worked under the temporary-to permanent employment status experienced more moral distress than other nurses (Table 4).

Table 4: Relationship between demographic characteristics and nurses' moral distress 


\begin{tabular}{|c|c|c|c|c|c|}
\hline & \multirow[t]{2}{*}{ Variables } & Intensity & \multirow{2}{*}{$\begin{array}{c}\text { p- } \\
\text { value }\end{array}$} & Frequency & \multirow{2}{*}{$\begin{array}{c}\text { p- } \\
\text { value }\end{array}$} \\
\hline & & Mean \pm SD & & Mean \pm SD & \\
\hline \multirow[t]{2}{*}{ Gender } & Male & $53 / 65 \pm 7 / 15$ & 0.10 & $53 / 53 \pm 6 / 00$ & 0.18 \\
\hline & Female & $51 / 12 \pm 5 / 25$ & & $52 / 04 \pm 5 / 06$ & \\
\hline \multirow[t]{2}{*}{ Marital status } & Single & $51 / 37 \pm 7 / 32$ & 0.76 & $51 / 57 \pm 6 / 03$ & 0.14 \\
\hline & Married & $51 / 67 \pm 4 / 44$ & & $52 / 58 \pm 4 / 47$ & \\
\hline \multirow[t]{3}{*}{ Position } & Nurse & $51 / 75 \pm 6 / 01$ & 0.22 & $52 / 58 \pm 5 / 29$ & 0.04 \\
\hline & Head nurse & $47 / 66 \pm 3 / 88$ & & $47 / 50 \pm 3 / 39$ & \\
\hline & Supervisor & $50 / 66 \pm 3 / 46$ & & $50 / 77 \pm 3 / 63$ & \\
\hline \multirow[t]{4}{*}{ Work shift } & Fixed morning & $50 / 52 \pm 4 / 90$ & 0.71 & $50 / 70 \pm 4 / 71$ & 0.23 \\
\hline & Fixed evening & $53 / 00 \pm 2 / 82$ & & $56 / 50 \pm 2 / 12$ & \\
\hline & Fixed night & 0 & & 0 & \\
\hline & Shifts in circulation & $51 / 64 \pm 6 / 01$ & & $52 / 42 \pm 5 / 29$ & \\
\hline \multirow{4}{*}{$\begin{array}{l}\text { Employment } \\
\text { Status }\end{array}$} & Permanent & $50.08 \pm 5.02$ & 0.005 & $51 / 53 \pm 5 / 09$ & 0.04 \\
\hline & $\begin{array}{l}\text { Under-a-contract } \\
\text { / Contractual }\end{array}$ & $51.21 \pm 4.90$ & & $53 / 04 \pm 4 / 66$ & \\
\hline & $\begin{array}{l}\text { Conscription law's } \\
\text { conscripts } \\
\text { Temporary-to Permanent }\end{array}$ & $52.23 \pm 7.95$ & & $50 / 30 \pm 6 / 45$ & \\
\hline & & $55 \pm 7.18$ & & $54 / 22 \pm 5 / 38$ & \\
\hline
\end{tabular}

The relationship between the intensity and frequency of moral distress and the age and work experience of the nurses was evaluated. The results of Pearson correlation coefficient test showed a statistically significant relationship between the nurses' work experience and the intensity of moral distress $(p=0.02)$.

Table 5: Relationship between frequency and intensity of moral distress with age and work experience 


\begin{tabular}{|l|c|c|c|}
\hline Variables & Mean \pm SD & Frequency & Intensity \\
\hline Age (year) & $31 / 72 \pm 5 / 75$ & $\mathrm{r}=-0.06$ & $\mathrm{r}=-0.13$ \\
& & $\mathrm{p}=0.39$ & $\mathrm{P}=0.08$ \\
\hline Years of nursing experience & $8 / 35 \pm 5 / 62$ & $\mathrm{r}=-0.11$ & $\mathrm{r}=-0.17$ \\
& & $\mathrm{p}=0.16$ & $\mathrm{p}=0.02$ \\
\hline
\end{tabular}

\section{Discussion}

The results of this study conducted to determine the level of moral distress and its related factors in nurses of Ardabil covid-19 wards indicated the moderate level of moral distress. Various studies performed in this field reported different results. The studies of Bayat et al. (2019), Ebrahimi et al. (2015), and Lusignani et al. (2016) conducted in Iran and Italy, respectively, showed the nurses' moral distress at moderate level $(13,29,30)$, which these results are in line with those of the present study. However, some other studies reported the low or high levels of nurses' moral distress. The study of Mosallanejad et al. (2021) entitled "Assessment of the level of moral distress in nurses and physicians caring for patients with Covid-19 in Jahrom" indicated the low level of moral distress among the participants (31). Moreover, the studies of Amiri et al., Houston et al., and Beyaffers et al. reported the high moral distress of the nurses in different wards (32-34). Factors including the cultural differences, lack of personal care, hospital equipment and facilities, workplace environment, economic situation, organizational rules and regulations, and nurses' ignorance of how to deal with the issue of moral distress could be considered as the reasons for the difference in the results.

Evaluating the relationship between the demographic characteristics and the level of moral distress of the nurses showed that there was a significant relationship between the type of employment and moral distress. Based on the results, the moral distress in temporary-to permanent nurses was more than other nurses. This may be due to the temporary work in the covid-19 conditions and their uncertain future. Further, the results showed a statistically significant difference between the level of moral distress and the position of nurses working in the Covid-19 wards. Nurses experienced more moral distress compared to the head nurses and supervisors, which is consistent with the results of the study of Wu Xiaoyan et al. (35). More and more direct exposure of the nurses to the patients with Covid-19 and fear of contracting the disease due to contacting with them can be the reasons justifying this issue.

In the present study, a negative correlation was observed between the nursing work experience and the intensity of nurses' moral distress, which indicated that the severity of moral distress decreased by increasing the years of nurses' duty, which is in line with the results of the study of Sadeghi et al. (13). It seems that the nurses can find solutions for adapting to these stresses by increasing the work experience and gaining more experience for more stressful environmental conditions. Based on the results, no significant difference was observed between the mean scores of the intensity and frequency of moral distress and the marital status of the nurses, which is consistent with those of the studies of Mosallanejad et al. and Sadeghi et al. $(31,13)$. Moreover, no significant relationship was found between 
the shift work and the intensity and frequency of moral distress, which is in line with the results of the study of Altaker et al. (15).

Completing the questionnaire by using self-report method was one of the limitations of this study since the individual characteristics such as job and psychological status can affect the answer to the questions. Therefore, it is recommended that another qualitative study should be performed on the nurses involved in the care of patients with corona virus for obtaining more accurate results.

\section{Conclusion}

The results indicated that almost all of the nurses evaluated in this study had some degree of moral distress. The frequency and intensity of the moral distress were found more in temporary-to permanent nurses compared to the nursing managers and nurses in other employment situations. Special attention should be paid to the mental state of the nurses involved with Covid-19 patients by organizational managers since moral distress in nurses can affect the quality and safety of the patient care (36). Using the experiences of the nurses, who were mostly present in the patients' beds and were involved in direct care of patients with various diseases can be useful in reducing the moral distress of covid-19 wards nurses. Further, the use of non-contract nurses in corona wards can be effective in reducing the moral distress.

\section{Abbreviations}

MD

Moral distress

ICU

Intensive care unit

COVID-19

Coronavirus Disease.

\section{Declarations}

\section{Acknowledgements}

We thank all the nurses who participated in this study and answered the questions in a critical situation.

\section{Authors' contributions}

MA designed the study, reviewed the results, and wrote the manuscript and approved the final manuscript. MP participated in data collection, data analysis, and writing the first draft of the manuscript. MA and MP read and approved the final manuscript.

\section{Funding}


This research did not receive any specific grant from funding agencies in the public, commercial, or nonprofit sectors.

\section{Availability of data and materials}

The data supporting the findings are available from the corresponding author on request by the journal.

\section{Declarations}

\section{Ethics approval and consent to participate}

The study was approved by the Ethics Committee in Biomedical Research at Ardabil University of Medical Sciences (ARUMS). The researchers obtained written informed consent from each participant as one of the criteria for them to join the study.

\section{Consent for publication}

Not Applicable.

\section{Competing interests}

The authors declare that they have no competing interests.

\section{Author details}

$1 \mathrm{MSc}$ in Nursing, Student Research Committee, School of Nursing and Midwifery, Ardabil University of Medical Sciences, Ardabil, Iran.

$2 \mathrm{PhD}$ in Nursing, School of Nursing and Midwifery, Ardabil University of Medical Sciences, Ardabil, Iran.

\section{References}

1. Abbaszadeh A, Torabi M, Borhani F, Shamsaei $F$. The place of ethics education in nursing in Iran. Journal of Bioethics. 2015;5(17):117-46[Persian].

2. Dehghani A, Radbeh F, Parviniannasab AM, Khaki S, Shamsizadeh M, Beyramijam M. Enactment of professional ethics standards compliance in patients and nurses prospective. Journal of Holistic Nursing and Midwifery. 2015;25(4):64-72 [Persian].

3. Khodaveisi M, Hassani P. Moral distress in Iranian nurses' experiences. Advance in Nursing and Midwifery. 2012;22:17-25 [Persian].

4. Mahmoodian $\mathrm{H}$, Sara $\mathrm{H}$. Compliance with the code of nursing ethics to deal HIV/AIDS patients among nurses work in internal and surgical wards of the hospitals in Shiraz. Iranian Journal of Medical Ethics and History of Medicine. 2018;11(1):100-17 [Persian]. 
5. Rabiee S, Khatiban M, Cheraghi MA. Nurses distress in intensive care unit: a survey in teaching hospitals. Iranian Journal of Medical Ethics and History of Medicine. 2012;5(2):58-69 [Persian].

6. Schluter J, Winch S, Holzhauser K, Henderson A. Nurses' moral sensitivity and hospital ethical climate: a literature review. Nurs. Ethics. 2008;15(3):304-21. doi: 10.1177/0969733007088357.

7. Moradzadeh A, Namdar Joyami E. Corona nurses' lived experience of moral distress while performing organizational duties. Quarterly Journal of Nursing Management. 2020;9(3):59-73 [Persian].

8. Elpern EH, Covert B, Kleinpell R. Moral distress of staff nurses in a medical intensive care unit. Am J Crit Care. 2005;14(6):523-30.

9. Morley G, Bradbury-Jones C, Ives J. What is 'moral distress' in nursing? a feminist empirical bioethics study. Nurs Ethics. 2020;27(5):1297-1314. https://doi.org/10.1177/0969733019874492.

10. Epstein EG, Delgado S. Understanding and addressing moral distress. The Online J Issues Nurs. 2010;15(3):Manuscript 1. doi: 10.3912/OJIN.Vol15No03Man01.

11. Naboureh A, Imanipour M, Salehi T, Tabesh H. The relationship between moral distress and selfefficacy among nurses in critical care and emergency units in hospitals affiliated to Ahvaz Jundishapur university of medical sciences in 2015. Journal of Rafsanjan University of Medical Sciences. 2015;14(6):443-54[Persian].

12. Hamric $A B$, Borchers $C T$, Epstein EG. Development and testing of an instrument to measure moral distress in healthcare professionals. AJOB Prim Res. 2012;3(2):1-9. https://doi.org/10.1080/21507716.2011.652337.

13. Sadeghi M, Ebrahimi H, Aghayan S. Evaluation of the moral distress and related factors in clinical nurses of Shahroud city. Iranian Journal of Psychiatric Nursing. 2015;3(3):20-28 [Persian].

14. Abbaszadeh A, Nakhaei N, Borhani F, Roshanzadeh $M$. The relationship between moral distress and retention in nurses in Birjand teaching hospitals. Iranian Journal of Medical Ethics and History of Medicine. 2013;6(2):57-66 [Persian].

15. Altaker KW, Howie-Esquivel J, Cataldo JK. Relationships among palliative care, ethical climate, empowerment, and moral distress in intensive care unit nurses. Am J Crit Care. 2018;27(4):295-302. doi: $10.4037 /$ ajcc2018252

16. Jalali K, Tabari-Khomeiran R, Asgari F, Sedghi-Sabet M, Kazemnejad E. Moral distress and related factors among emergency department nurses. Eurasian J Emerg Med. 2019;18(1):23. doi: 10.4274/eajem.galenos.2018.78941

17. Humphries A, Woods M. A study of nurses' ethical climate perceptions: compromising in an uncompromising environment. Nurs Ethics. 2016;23(3):265-76. doi: 10.1177/0969733014564101.

18. Joolaee $S$, Jalili $H$, Rafiee F, Haggani $H$. The relationship between nurses' perception of moral distress and ethical environment in Tehran University of Medical Sciences. Iranian Journal of Medical Ethics and History of Medicine. 2011;4(4):56-66 [Persian].

19. Mealer M, Moss M. Moral distress in ICU nurses. Intensive Care Med. 2016;42(10):1615-17. doi: 10.1007/s00134-016-4441-1. 
20. Hossain F, Clatty A. Self-care strategies in response to nurses' moral injury during COVID-19 pandemic. Nurs Ethics. 2021;28(1):23-32. doi: 10.1177/0969733020961825.

21. Donkers MA, Gilissen VJ, Candel MJ, van Dijk NM, Kling H, Heijnen-Panis R, et al. Moral distress and ethical climate in intensive care medicine during COVID-19: a nationwide study. BMC Med Ethics. 2021;22(1):1-12. doi: 10.1186/s12910-021-00641-3.

22. Mo Y, Deng L, Zhang L, Lang Q, Liao C, Wang N, Qin M, Huang H. Work stress among Chinese nurses to support Wuhan in fighting against COVID-19 epidemic. J Nurs Manag. 2020;28(5):1002-9. doi: 10.1111/jonm.13014.

23. Galbraith N, Boyda D, McFeeters D, Hassan T. The mental health of doctors during the COVID-19 pandemic. BJPsych Bull. 2021;45(2):93-97. doi: 10.1192/bjb.2020.44.

24. Cacchione PZ. Moral distress in the midst of the COVID-19 pandemic. SAGE Publications Sage CA: Los Angeles, CA; 2020.

25. Turale S, Meechamnan C, Kunaviktikul W. Challenging times: ethics, nursing and the COVID-19 pandemic. Int Nurs Rev. 2020;67(2):164-67. doi: 10.1111/inr.12598.

26. McKenna H. Covid-19: ethical issues for nurses. Int J Nurs Stud. 2020;110:103673. doi: 10.1016/j.ijnurstu.2020.103673.

27. Jia Y, Chen O, Xiao Z, Xiao J, Bian J, Jia H. Nurses' ethical challenges caring for people with COVID19: a qualitative study. Nurs Ethics. 2021;28(1):33-45. doi: 10.1177/0969733020944453.

28. Borhani F, Mohammadi S, Roshanzadeh M. Moral distress and its relationship with professional stress in nurses. Iranian Journal of Medical Ethics and History of Medicine. 2014;6(6):1019[Persian].

29. Bayat M, Shahriari M, Keshvari M. The relationship between moral distress in nurses and ethical climate in selected hospitals of the Iranian social security organization. J Med Ethics Hist Med. 2019;12:8. https://doi.org/10.18502/jmehm.v12i8.1339.

30. Lusignani M, Giannì ML, Re LG, Buffon ML. Moral distress among nurses in medical, surgical and intensive-care units. J Nurs Manag. 2017;25(6):477-85. doi: 10.1111/jonm.12431.

31. Mosalanezhad L, Abiri S, Kalani N. Moral distress level in nurses and physicians caring for patients with COVID-19: a cross-sectional descriptive study in 2020. Education and Ethics in Nursing. 2020;9(3):1-8[Persian].

32. Ameri M, Mirhashemi B, Hosseini SS. Moral distress and the contributing factors among nurses in different work environments. Journal of Nursing and Midwifery Sciences. 2015;2(3):44-49[Persian].

33. Houston S, Casanova MA, Leveille M, Schmidt KL, Barnes SA, Trungale KR, et al. The intensity and frequency of moral distress among different healthcare disciplines. Clin Ethics. 2013;24(2):98-112.

34. Beyaffers HA, Woldetsadik MT, Gizaw AB. Predictors of moral distress among nurses working in Jimma University Medical Center, South West Ethiopia. Front Nurs. 2020;7(4):369-77. doi: 10.2478/fon-2020-0046. 
35. Wenwen Z, Xiaoyan W, Yufang Z, Lifeng C, Congcong S. Moral distress and its influencing factors: a cross-sectional study in China. Nurs Ethics. 2018;25(4):470-80. doi: 10.1177/0969733016658792.

36. Schaefer R, Zoboli ELCP, Vieira M. Identification of risk factors for moral distress in nurses: basis for the development of a new assessment tool. Nurs Inq. 2016;23(4):346-57. doi: 10.1111/nin.12156. 